\title{
A Gravidez da Terapeuta e seus Reflexos no Processo Psicoterápico
}

\author{
Cláudia Backes Tonon \\ Instituto Fernando Pessoa \\ Patrícia Fasolo Romani ${ }^{1}$ \\ Pontifícia Universidade Católica do Rio Grande do Sul \\ Rosaura Grossi \\ Instituto Fernando Pessoa
}

\begin{abstract}
RESUMO - Este artigo aborda as peculiaridades do setting terapêutico mediante a gravidez da terapeuta. O objetivo principal deste estudo foi investigar e compreender a influência da gestação na relação terapêutica, sendo que as terapeutas engravidaram durante o tratamento dos pacientes. Trata-se de uma pesquisa qualitativa, observacional, de cunho exploratório; para coleta de dados, elegeu-se o método clínico e a entrevista semi-estruturada, e mediante o encontrado, a análise de conteúdo. Os resultados mostram que a gravidez tem reflexos intensos, viabilizando que conflitos e experiências infantis sejam revividos e até mesmo resignificados. Os sentimentos mais evidenciados pelos pacientes foram: inveja, temores de desamparo e abandono, e conflitos relacionados à identificação com a figura materna.
\end{abstract}

Palavras-chave: gravidez; relação terapêutica; psicoterapia.

\section{The Therapist's Pregnancy and its Consequences on the Psychotherapeutic Process}

\begin{abstract}
This article discusses the peculiarities of a therapeutic setting during pregnancy of the therapist. The main objective of this study was to investigate and understand the influence of pregnancy on the therapeutic relationship considering that the therapists conceived during the treatment of their patients. This work is an observational qualitative study of exploratory nature. The clinical method and semi-structured interview were used for data collection. After this phase the data were analyzed using content analysis. The results show that pregnancy has intense consequences, enabling infantile conflicts and experiences being revived and even reinterpreted. The most demonstrated feelings by the patients were: envy, fear of abandonment and neglect, and conflicts related to identification with a mother figure.
\end{abstract}

Keywords: pregnancy; therapeutic relationship; psychotherapy.

A vivência de uma gravidez, do ponto de vista mais amplo, pode ser caracterizada como uma crise biopsicossocial e vital que influencia a dinâmica psíquica individual e relacional da gestante (Buchabqui, Abeche \& Brietzke, 2002). É um momento de importantes reestruturações na vida da mulher e nos papéis que esta exerce; durante esse período, ela passa da condição exclusiva de filha para a de mãe, revivendo experiências anteriores, além de reajustes nos âmbitos conjugal, socioeconômico e profissional. (Soifer, 1980).

Com a gestação, a mulher necessita se adaptar as inúmeras mudanças que acontecem no seu corpo, aos riscos reais e imaginários inerentes a sua condição e ao parto, e as expectativas que são geradas em torno do bebê, o que contribui para a progressão da ansiedade, à medida que o parto se aproxima (Pacheco, Figueiredo, Costa \& Pais, 2005; Freitas, 2001). Durante a gestação, a identidade materna é construída por meio de uma imagem idealizada de si como mãe e, também, do bebê como filho.

A vivência dessa etapa é influenciada por inúmeros fatores, de ordem tanto intrapsíquica como contextual, tais como: a estrutura de personalidade da gestante, o nível de resoluções de seus conflitos, o suporte conjugal e familiar e as expectativas acerca do bebê (Soifer, 1980).

1 Endereço para correspondência: Rua Dona Laura, 228/ 405 POA, Moinhos de Vento. Porto Alegre, RS. CEP 90430-090. E-mail: pattyfaro@hotmail.com.
A gravidez da terapeuta é um tema pouquíssimo estudado e consideravelmente experienciado na relação psicoterápica. Acredita-se que essa modificação real, concreta e reveladora da vida da terapeuta possa interferir direta e indiretamente no curso do tratamento, bem como exercer um papel relevante nas intervenções e na transferência estabelecida. Segundo Lax (1969), constitui uma experiência única para o paciente, altamente carregada de estímulos, evocadora de conflitos, fantasias e desejos infantis profundamente reprimidos.

Conforme Luz, Keidann e Dal Zot (2006), a gravidez se faz presente no setting de uma forma intensa. Assim como uma doença física séria do analista causaria um impacto no processo analítico, o mesmo acontece com a gravidez. O foco deve ser a análise de como a situação analítica é alterada sob estas circunstâncias e como pode ser mantida. Mesmo que se evite, observam-se mudanças. Estas variam desde as mais objetivas e formais, como a necessidade de trocas de horários para a realização de exames e consultas da terapeuta, até as modificações mais lentas, graduais e sutis. Dentre estas, salientam-se as mudanças internas que se apresentam na mente da terapeuta e estão presentes durante as sessões, de forma diferente com cada paciente, mobilizadas de acordo com a configuração da patologia do paciente, mas, principalmente, mobilizadas pela interação de cada dupla. O momento do tratamento e o grau de confiança existente na dupla também determinam como a gravidez vai influenciar os rumos terapêuticos. 
Entender o sentido e as repercussões desta vivência é fundamental se a considerarmos como variável no setting durante nove meses, com uma interrupção contratada previamente ou não, e com a posterior retomada do tratamento em uma situação que envolve significativas alterações.

Esta pesquisa teve como objetivos principais descrever e aprofundar a relação terapêutica durante o período gestacional da terapeuta, sob o ponto de vista da mesma.

\section{Método}

Realizou-se um estudo qualitativo, observacional, de cunho exploratório, através do método clínico embasado na psicanálise e aliado ao referencial teórico da psicologia do ego. O princípio fundamental no método desenvolvido por Freud, no qual, as elaborações mentais de seus analisandos exerciam impacto sobre ele e contribuíam tanto para sua auto-análise, como para o desenvolvimento da teoria. Assim, entendemos que de forma similar, o método clínico de pesquisa oferece oportunidade tanto ao pesquisador, como ao entrevistado, de conhecer o aspecto da realidade que os cerca, ao mesmo tempo em que se revela o conhecimento sobre o objeto pesquisado (Gomes e Resende, 2004).

\section{Participantes}

As participantes foram oito terapeutas que já vivenciaram uma gestação durante o processo psicoterápico, sem que isto estivesse previsto no contrato; foram localizadas através de indicação de outras terapeutas, e convidadas a participar mediante contato telefônico. Posteriormente, foram submetidas a uma entrevista semi-estruturada, mas antes, houve um piloto a fim de adaptar as perguntas à população-alvo. As entrevistas foram gravadas e posteriormente transcritas, sendo descartadas após a conclusão do estudo. Os nomes utilizados são fictícios, a fim de salvaguardar a identidade das participantes.

\section{Instrumentos e procedimentos}

As questões norteadoras consideraram o impacto desse dado de realidade na relação terapêutica, suas derivações e a influência tanto positiva, quanto negativa no processo terapêutico. Os dados foram avaliados a partir da Análise de Conteúdo (Bardin, 1991), que utiliza procedimentos sistemáticos e objetivos de descrição do conteúdo das mensagens. Os elementos de conteúdo foram agrupados por parentesco de sentido e por repetições, criando-se categorias.

\section{Resultados e Discussão}

As categorias levantadas e suas respectivas interpretações, fundamentadas nos referenciais teóricos inicialmente propostos são apresentadas na sequencia e organizam a seção de resultados.

\section{Percepções da terapeuta acerca da própria gravidez}

Nesta categoria foram incluídas todas as verbalizações referentes às expectativas da terapeuta frente a sua gestação, bem como se esta foi ou não planejada. Das oito terapeutas entrevistadas, sete referiram que a gravidez foi planejada; esta decisão interfere significativamente na organização e elaboração das mudanças subseqüentes:"Foi planejada, então na realidade já houve uma preparação, uma preocupação em relação ao processo dos pacientes nesse período" (Jussara).

Observou-se que, mesmo não tendo sido desejada naquele momento, engravidar era um dos objetivos da outra terapeuta: "Na realidade, a minha gravidez não foi planejada, devido a um problema de saúde que, a princípio, eu não engravidaria. Então, eu comecei a fazer um tratamento pra, na teoria, ficar grávida uns oito meses depois, e nesse meio tempo eu engravidei" (Potira).

Luz et al. (2006) salientam que a confirmação de que a gravidez está evoluindo bem se caracteriza por uma etapa em que uma agradável e prazerosa sensação toma conta da mente da terapeuta, pois a gravidez desejada se apresenta como algo que se remete a um estado primitivo de gratificação narcisista intensa, ilustrado a seguir: "Eu me lembro que eu me sentia muito melhor pra trabalhar, é como se a vida passasse a ter um colorido diferente, eu acho que não se explica muito isso, mas eu me sentia com mais pique pra trabalhar, eu me sentia mais inteira, eu me sentia mais presente, acho que passei a entender mais algumas coisas de algumas pacientes" (Jussara).

A gravidez é um período de modificação na aparência, de aumento da vulnerabilidade física e emocional, com mudança considerável de papéis. Seis entrevistadas vivenciaram um período gestacional tranqüilo, apesar de ser repleto de transformações e alguns imprevistos: "Pra mim foi bonito e ao mesmo tempo um pouco difícil, pois dá a impressão que a gravidez altera os pacientes, altera a relação que se têm com eles, altera o setting (...) Estar grávida altera a imagem física também, a barriga cresce, o corpo vai mudando e a psicoterapia vira uma relação a três, pois há uma nova vida entre as vidas que se encontram no processo terapêutico" (Yara).

Duas terapeutas tiveram complicações ao longo da gestação. Quando a saúde da terapeuta ou do seu bebê está ameaçada, é de suma importância recontratar as combinações inicialmente feitas pela dupla, minimizando assim, a ansiedade de separação de ambos os lados: "Foi um pouco diferente, porque na verdade eu não cheguei ao final da gestação, então o processo mais complicado foi no final, como ela nasceu de sete meses, o que aconteceu foi que a minha obstetra de uma hora pra outra me disse que a partir de qualquer momento eu poderia ter que baixar hospital e aí eu tive que começar a trabalhar isso com os pacientes". (Jussara).

\section{Reações dos pacientes frente à gestação da terapeuta}

Esta categoria foi composta pelo conjunto de verbalizações em que as participantes expressam as reações dos pacientes ao longo do período gestacional da terapeuta, bem como a forma da terapeuta anunciar a gestação. É importante salientar que aqui não entraram aspectos referentes à técnica 
terapêutica e sim, à percepção da terapeuta quanto às reações despertadas nos pacientes.

Quanto à comunicação verbal sobre a gestação, cinco entrevistadas relataram que a fizeram, sendo que duas não tinham essa intenção inicialmente, mas acabaram contando em função de algumas complicações: "Não era a minha intenção a comunicação formal, mas acabou acontecendo em função do sangramento, porque tive que cancelar consultas" (Maiara).

"No início, eu não coloquei para os pacientes da minha gestação, eu esperei que cada um pudesse trazer alguma observação, perceber a barriga crescer para ir trabalhando a percepção e o jeito deles lidarem com isso, mas depois, por causa do risco de nascer antes, achei melhor, então, explicar" (Jussara).

Marriot (1993) considera que a vivência deste momento pode fortalecer a capacidade da terapeuta de manejar seus próprios conflitos e ansiedades, bem como as demandas físicas, sendo natural a decisão da terapeuta de ocultar a gravidez até o final do terceiro mês, por seus temores e ansiedades quanto aos riscos de aborto ou malformação fetal.

Três entrevistadas optaram por esperar até os pacientes se manifestarem: "Esperei que os pacientes notassem a gravidez e, a maioria tocou no assunto logo que a barriga começava a crescer, demonstrando curiosidade" (Iracema). Lax (1969) salienta que a terapeuta pode adiar as verbalizações dos pacientes sobre o assunto da gravidez em virtude do medo da hostilidade que estas poderiam trazer ou conter.

Quanto às reações dos pacientes frente à gestação, a maioria das terapeutas destacou reações semelhantes como receptividade, curiosidade e cuidados quanto ao "estado" da terapeuta: "A maioria dos pacientes respeitou muito esse momento, demonstrando uma curiosidade normal, algumas perguntas do tipo: é menino ou menina? Já tem outros filhos? Pensa em parar muito tempo?" (Iracema). "Eu percebia, assim, que eles queriam olhar a barriga e saber como é que era, que eu falasse, ficavam me olhando e me admirando (...) muito cuidado, sabe, eu vejo que todas as pessoas têm a tendência de cuidar da grávida, se preocupar, querer saber se tá comendo, se ta cansada, se não está.” (Tainá).

A percepção da gravidez acontece de forma particular e específica com cada paciente. As reações são as mais variadas, conforme a conflitiva e personalidade de cada indivíduo (Luz et al., 2006): "Eu tive uma paciente que no início, quando ela vinha demonstrando que percebia, ela olhava para a barriga, mas nunca tocou no assunto, mas é porque ela tinha história de perda recente, de um aborto (...)" (Jussara).

Nadelson, Notman, Arons e Feldman (1974) descrevem as modificações produzidas na relação terapêutica, ressaltando uma preocupação dos pacientes atendidos acerca da sexualidade da terapeuta. A gravidez, via de regra, é a prova cabal da vida sexual da terapeuta e automaticamente, pela transferência, também dos pais, o que reporta o paciente a cena primária e ao Complexo de Édipo.

Mecanismos de defesa como a negação, são empregados como tentativa de lidar com as angústias despertadas pela gestação; quanto mais regressivo for o paciente, maior a probabilidade de negar o fato: "Um paciente adulto que, no $6^{\circ}$ mês de gestação ainda não havia reparado e, quando falei, se assustou, negando o assunto nas sessões posteriores à notícia." (Iracema)

O temor do desamparo muitas vezes é concebido como o pivô da entrada e da saída da psicoterapia, e a dificuldade ou mesmo a incapacidade de sua elaboração coloca em questão a possibilidade de término do tratamento (Lourenço, 2005). "Muitos negam a gestação da terapeuta; pra alguns, era como se eu não estivesse grávida. Chegavam a desconsiderar o novo contrato e não falavam sobre o afastamento que estava chegando." (Yara)

\section{Relação Terapêutica}

Aqui foram abrangidas as percepções das terapeutas frente às alterações no vínculo da díade, incluindo conceitos técnicos, tais como: transferência, contratransferência, aliança terapêutica e neutralidade, exemplificados através das subcategorias descritas identificadas nos sub-títulos.

\section{Transferência e contratransferência}

Transferência é a tentativa de revivência de situações e fantasias da infância do paciente, através da relação estabelecida com o terapeuta, no setting (Sandler, Dare e Holder, 1986). Na transferência, o terapeuta é colocado no lugar de uma das imagos primordiais do indivíduo: paterna, fraterna ou materna (Lourenço, 2005).

Dependência, perda, abandono, separação, inveja, ciúmes e competição, exclusão, medo e repulsa sobre a anatomia e sexualidade feminina, desejos e medo de engravidar, idealização e desvalorização, ansiedade e culpa por desejos de morte do feto ou da terapeuta, preocupações de reparação são os principais sentimentos transferenciais despertados nos pacientes, na concepção de Bassen (1988).

No que diz respeito aos aspectos transferenciais, emergiram conteúdos de abandono e rejeição, segundo três entrevistadas: "Teve uma paciente que estava em processo de alta, e aí a gente teve que fazer com que essa alta fosse prolongada, porque ela se sentiu meio que abandonada." (Potira)

A raiva usualmente está associada ao sentimento de abandono, rejeição e inveja, como no exemplo a seguir: "Houve alteração apenas com uma paciente adulta que já vinha resistente no decorrer da gestação, trazendo aspectos transferenciais fortes de raiva, de abandono, pois era uma pessoa muito sozinha." (Tainá)

Segundo Klein (1974), a inveja designa um sentimento primário e inconsciente de avidez em relação a um objeto que se quer destruir ou danificar; aparece desde o nascimento e é inicialmente dirigida contra o seio da mãe. Seis das oito participantes detectaram a inveja em alguns pacientes: "Uma paciente que tinha feito vários abortos, e que tava tentando engravidar e não conseguia engravidar. Então, assim, o fato de eu estar grávida foi muito difícil pra ela (...) após o meu retorno, ela relatou ter ido ao hospital ver se ele estava bem, e disse que de certa forma o bebê tinha tirado o lugar dela e que ao vê-lo bem sentiu algo ruim, de rivalidade." (Potira)

Uma vez que a terapeuta representa as imagos parentais, o paciente pode rivalizar com o futuro bebê, sentindo- 
-o como um irmão que virá roubar o seu lugar, principalmente se o conflito original não foi adequadamente elaborado. Goldsmid e Féres-Carneiro (2007) afirmam que a chegada do irmão é a chegada do "estrangeiro", daquele que, com sua presença, perturba o equilíbrio constituído. Segundo Silveira (2009), a rivalidade dentro do universo fraterno nem sempre se apresenta de maneira explícita. Alguns irmãos cultivam seus sentimentos de inveja e ciúme veladamente, de forma sigilosa, outros atuam de forma camuflada, dissimulada.

Joseph (1992) salienta que uma pessoa excessivamente invejosa pode achar tão difícil tolerar que outra tenha alguma coisa para lhe dar, que ela não pode reconhecer ou usar a outra pessoa construtivamente. Quando o indivíduo invejoso não consegue ver nada a elogiar ou a valorizar no outro, encontra sempre alguma razão para duvidar da outra pessoa ou derrubá-la. Por outro lado, a inveja muito intensa conduz a crítica incessante ou a constantes alfinetadas, conforme o relato: "Eu sentia que ela sentia ciúmes de mim, eu tinha essa impressão, né, às vezes tecia comentários que eu estava engordando, que eu estava com muito seio, que eu estava com peito grande" (Moema).

A inveja da mulher grávida encobre intensa voracidade e privação, o que desencadeia maior preocupação da terapeuta com os pacientes invejosos, além de mais sentimento de raiva em ambos (Luz et al., 2006).

Evocada por conflitos infantis ou conflitos com a feminilidade, a hostilidade do paciente é capaz de desencadear ansiedades na terapeuta grávida (Luz et al., 2006). A capacidade do terapeuta de suportar os sentimentos que lhe são despertados, decifrando-os e utilizando-os no entendimento do paciente é chamada de contratransferência (Sandler, Dare e Holder, 1986).

Quanto à contratransferência, seis das oito terapeutas identificaram tal período como de maior fragilidade ou menor disponibilidade em relação ao processo terapêutico: "Eu me sentia muito irritada." (Potira) "Senti que gostava mais de atender aqueles que aceitaram melhor a minha gravidez, como se isso significasse que minha filha estivesse sendo acolhida." (Janaína)

Para Lax (1969) a terapeuta grávida sofre um aumento em sua vulnerabilidade, sendo as reações observadas evocadas por intensas reações transferenciais, e a forma que a contratransferência toma pode estar relacionada com os conflitos infantis da terapeuta. Uma reação freqüente ressaltada pelo autor e também por Brodacz e Mondrzak (1985), é o sentimento de culpa frente aos pacientes por causa de fantasias relacionadas à interrupção dos atendimentos e aos desejos da terapeuta de dedicar-se à maternidade, caracterizando conflitos primitivos de rivalidade infantil, coincidindo com a opinião de Tainá: “(...) eu lembro que às vezes eu me pegava assim: ah que vontade de tá em casa, ou fazendo outra coisa e não falando de problemas! Será que o bebê vai perceber isso tudo? Será que o bebê tá escutando isso tudo? Eu me lembro que às vezes eu tinha vontade de não estar ali." (Tainá)

Ainda sob o aspecto da vulnerabilidade, Etchegoyen (1993) considera que a analista grávida requer uma demanda maior de recursos para o trabalho psíquico. Há um envolvimento narcísico da terapeuta com seu corpo, nos aspectos internos e externos.
Surgem medos, ansiedades primitivas sobre o interior do corpo, receio de danificar o feto ou ser machucada por ele, inveja e ciúmes fraternos. Pode haver intensificação de defesas e temores de ser atacada, necessitando proteger o feto Etchegoyen (1993). Esses conteúdos, em alguns casos, são provenientes da identificação projetiva, que significa colocar partes do self do paciente para dentro do objeto- terapeuta.

Quando a terapeuta não percebe a identificação projetiva do paciente, tende a pensar, sentir e agir em resposta aos conteúdos despejados, de forma contraidentificada, perdendo de usar positivamente o que lhe foi comunicado através da contratransferência.

\section{Aliança Terapêutica}

De acordo com Gomes (2004), a aliança terapêutica é a base indispensável do tratamento baseado na teoria psicanalítica; é uma relação positiva e estável entre terapeuta e paciente, onde existe confiança e credibilidade. Para Greenson (1981), trata-se de um fenômeno transferencial relativamente racional, onde as funções do ego do paciente desempenham um papel importante.

As participantes acreditam que a interferência da gestação da terapeuta na aliança terapêutica é relativa, ou seja, depende desde fenômenos transferenciais e contratransferenciais, até a história de vida de cada paciente.

\section{“(...) alguns podem se beneficiar por a gravidez facilitar o aparecimento de conteúdos que antes não estavam sendo trabalhados, ou eram trazidos com dificuldade; outros podem ficar muito atrapalhados, ou mesmo não suportar (...) levando até ao abandono." (Maiara)}

Segundo Luz et al. (2006), mudanças internas se apresentam na mente da terapeuta e estão presentes durante as sessões, de forma diferente com cada paciente, mobilizadas de acordo com a configuração da patologia do paciente, mas, principalmente, mobilizadas pela interação de cada dupla. $\mathrm{O}$ momento do tratamento e o grau de confiança existente na dupla também determinam como a gravidez vai influenciar os rumos terapêuticos.

\begin{abstract}
"Eu penso que as duas coisas (...) eu penso que pode ser muito favorável, na medida em que a gente consegue trabalhar. Vai depender um pouco da tua relação com o paciente, da patologia do paciente, de como está a tua gestação também. Se tu tá em terapia ou não, como tu tá sendo supervisionada, como é que as coisas vão fluindo nisso." (Potira)
\end{abstract}

\section{Neutralidade}

Nesta subcategoria entraram as verbalizações referentes à postura da terapeuta ou mudanças na interação entre a díade quanto à figura de anonimato. Neutralidade na psicoterapia é a posição comportamental e emocional do terapeuta em relação ao paciente, onde aquele deixa de lado seus valores, crenças e preconceitos a fim de escutar e ajudar este outro, 
sem julgá-lo, mas sim, valendo-se de empatia e tolerância (Eizirik, 1996; Money-Kyrle, 1990).

A gravidez da terapeuta torna-se visível ao paciente, quebrando de certa forma o conceito de neutralidade, pois se configura um momento pessoal e íntimo da vida da terapeuta, que afeta setting e curso do tratamento (Eizirik, 1996).

Todas as participantes apontaram alterações importantes relacionadas à neutralidade, associadas, inclusive, as mudanças físicas. Outro destaque foi a curiosidade dos pacientes, acompanhada de questionamentos sobre a família da terapeuta: "Na questão da postura eu acho que fica mais complicado, quando tu fica grávida, tu tem que te expor mais, porque é uma coisa da tua vida, que eles estão vendo que existe. Às vezes, tá, tu tá com aliança, vêem que tu é casada, mas ninguém fica perguntando do teu marido, aí depois que tu volta eles querem saber o nome do bebê, querem saber se é bonitinho, querem saber se é parecido contigo, querem olhar pra ti e ver se tá gorda, se tá magra, como é que tu ficou depois de ter filho, o que tu fala (ou faz) depois de ser mãe, que era uma coisa que os pacientes perguntavam bastante (...) quando eu retornei, que apareceram essas coisas, assim, que tu acaba tendo que sair um pouco daquele lugar neutro, porque bom, é uma coisa da realidade que eles viram, que eles acompanharam, que tu tem que responder" (Janaína).

A gravidez da terapeuta permite que o paciente elabore e renuncie a imagem da mãe onipotente; para que a concepção ocorra, a mãe precisa do pai e, portanto, a mãe-terapeuta já não está mais envolvida exclusivamente com o paciente (Mariotti, 1993).

\footnotetext{
“Alguns traziam comentários que antes não apareciam na terapia, talvez porque antes a barriga também não aparecia (...) quando a barriga começa a aparecer mais os pacientes começam a falar mais, a perguntar mais, o que é estranho, pois neste momento a terapeuta deixa de ser aquela "folha em branco" e passa a ser uma pessoa real, passando pelo prisma da sexualidade também. A terapeuta estar grávida implica em ela ter uma vida sexual, em ela ter alguém, em ela ser mulher... digamos que traz dados intimos e de realidade a um universo que antes era mais neutro" (Yara).
}

De acordo com Zimermann (1999) a pessoa real do terapeuta pode constituir-se num valioso instrumento de trabalho, sendo capaz de propiciar ao paciente uma nova e reparadora experiência de relação objetal, desde que este terapeuta tenha saúde e equilíbrio para ser continente tanto de suas próprias angústias como das do paciente e, podendo assim, oferecer-se como um objeto suficientemente bom.

\section{Interrupção do Tratamento}

Tal categoria faz referência ao número de interrupções que aconteceram, abrangendo desde o momento inicial da gestação até o retorno das terapeutas ao trabalho, após o período de afastamento.

Das oito entrevistadas, duas mantiveram todos os atendimentos anteriores ao período gestacional. Em contrapartida, quatro relataram o abandono do tratamento por parte de alguns pacientes: "Houve dois abandonos que considero totalmente relacionados à gravidez. De uma paciente que estava muito braba com a filha que tinha ficado grávida há poucos meses, e de uma paciente que há pouco tempo tinha ficado sabendo que não poderia ter filhos." (Maiara)

"Houve quatro ou cinco interrupções. Foi um numero bem significativo. Acredito que tenha muita relação com a gravidez e em alguns casos eu até trabalhei a questão, até porque a gravidez é algo que não é contratado, o paciente não espera por isso". (Yara)

Quinodoz (1993) refere que quando um analisando está mais próximo da posição depressiva, ou seja, mais integrado, está mais em contato consigo mesmo e com os outros, e é capaz de comunicar verbalmente o que sente para a pessoa do analista, que é visto como uma pessoa total, diferente da visão e da estrutura dos pacientes que abandonaram o tratamento.

Apesar da gravidez da terapeuta despertar uma série de reações e sentimentos nos pacientes, a maior parte destes acaba prosseguindo no processo terapêutico e suportando esse período de interrupção, considerado mais significativo que finais de semana ou férias.

\section{Considerações Finais}

A gravidez da terapeuta inevitavelmente acarreta variações no processo psicoterápico, modificando a relação da dupla e agindo consciente ou inconscientemente sobre fatores psíquicos de ambos; a entrada de um terceiro elemento - o bebê - propicia a emergência e o manejo de vivências infantis do paciente, oportunizando o reaparecimento de sentimentos e conflitos no setting talvez antes mesmo do esperado. Por se tratar de uma evidência sobre a vida pessoal da terapeuta, coloca em cheque a neutralidade e interfere significativamente no curso do tratamento.

As reações mais evidenciadas pelos pacientes frente à gestação das terapeutas foram: inveja, temores de desamparo e abandono, além de conflitivas sobre a identificação com a figura materna, o Complexo de Édipo e a fratria.

A maior parte dos pacientes suporta a interrupção - considerada mais significativa que as férias do terapeuta - e prossegue com o tratamento. Existem fatores que influenciam tal continuidade, tais como a etapa do tratamento quando o fato ocorre, a percepção e interpretação adequada da transferência, a compreensão e manejo da contratransferência em benefício do paciente, uma aliança terapêutica genuína e a capacidade de vinculação do paciente e o tipo de patologia do paciente.

Sugere-se a realização de novos estudos que aprofundem a temática abordada, visando o aprimoramento da questão na prática clínica.

\section{Referências}

Bardin, L. (1991). Análise de Conteúdo. Lisboa: Edições.

Bassen, C. (1988). The impact of the analyst's pregnancy on the course of analysis. Psychoanalytic Inquiry, 8, 291-298. 
Brodacz, G., \& Mondrzak, V. S. (1985). Manifestações de pacientes à gravidez de suas terapeutas. Revista de Psiquiatria do Rio Grande do Sul, 7, 115-117.

Buchabqui, J. A., Abeche, \& A. M., Brietzke E. (2002). Assistência pré-natal. In F. Freitas, S. H. Martins-Costa, J. G. L. Ramos, \& J. A. Magalhães (Eds.), Rotinas em Obstetricia. (pp. 23-37) (4a ed). Porto Alegre: Artmed.

Eizirik, C. L. (1996). Masculinidad, feminidad y relación analitica: cuestiones contratransferenciales. Psicoanálisis en America Latina - Teoria y técnica, FEPAL - Federación Psicoanalítica de América Latina; IPA - Asosiación de Psicoanálisis, pp.121138.

Etchegoyen, A. (1993). The analyst's pregnancy and its consequences in her work. Internacional Journal of Psychoanalysis, 74, 141-149.

Freitas, P. P. (2001). Ansiedade e gravidez. Intervencao psicossocial em gravidas com alta ansiedade. Tese Doutorado, Instituto de Ciências Abel Salazar. Porto: ICBAS.

Goldsmid, R., \& Féres-Carneiro, T. (2007). A função fraterna e as vicissitudes de ter e ser um irmão. Psicologia em Revista, 13(2), 293-308.

Gomes, A. J. da S, \& Resende, V. da R. (2004). The present father: Discovering the fatherhood in a contemporary family. Psicologia: Teoria e Pesquisa, 20(2).

Greenson, R, R. (1981). A técnica e a prática da psicanálise. Rio de Janeiro; Imago Editora.

Joseph, B. (1992). Equilíbrio Psíquico e Mudança Psíquica. Rio de Janeiro: Imago.

Klein, M. (1974). Inveja e gratidão: um estudo das fontes do inconsciente. Rio de Janeiro: Imago.

Lax, R. (1969). Some considerations about transference and counter transference manifestations evoked by the analyst's pregnancy. Internacional Journal of Psychoanalysis, 50, 363-372.

Lourenço, L. C.A. (2005). Transferência e complexo de édipo, na obra de Freud: Notas sobre os destinos da transferência. Psicologia: Reflexão e Crítica, 18 (1).
Luz, A. B., Keidann, C. E., \& Dal Zot, J. S. (2006) Contratransferência e os fatores da vida pessoal do psicoterapeuta e/ou psicanalista. In J. Zaslavsky; M. J. P. dos Santos (Eds), Contratransferência - Teoria e Prática Clínica (pp. 269-284). Porto Alegre: Artmed.

Mariotti, P. (1993). The analyst's pregnancy: patient, analyst, and the space of the unknown. Internacional Journal of Psychoanalysis, 74, 51-164.

Money-Kyrle, R. (1990). Contratransferência normal e alguns de seus desvios. In E. M. R. Barros (Ed.), Melanie Klein hoje: desenvolvimentos da teoria e da técnica (pp. 76-88). Rio de Janeiro: Imago.

Nadelson, C., Notman, M., Arons, E., Feldman, J. (1974). The pregnant therapist. American Journal of Psychiatry, 131,110711.

Pacheco, A. P., Figueiredo, B., Costa, R. A., Pais, A. (2005). Antecipação da experiência de parto: mudanças desenvolvimentais ao longo da gravidez. Revista Portuguesa de Psicossomática. 7, 7-41.

Quinodoz, J. M. (1993). A solidão domesticada: a angústia de separação em psicanálise. Porto Alegre: Artes Médicas.

Sandler, J., Dare, C., \& Holder, A. (1986). O paciente e o analistafundamentos do processo psicanalítico. Rio de Janeiro: Imago.

Silveira, M. L. C. (2009). Da rivalidade ao amor: irmãos para sempre. Investigação, 9(1), 33-44.

Soifer, R. (1980). Psicologia da gravidez, parto e puerpério. Porto Alegre: Artes Médicas.

Zimerman, D. E. (1999). Fundamentos psicanaliticos teoria, técnica e clínica: uma abordagem didática. Porto Alegre: Artmed.

Recebido em 23.03.2009

Primeira decisão editorial em 13.07.2010

Versão final em 08.02.2011

Aceito em 02.03.2011 